\title{
Developmental Regulation of Spontaneous Activity in the Mammalian Cochlea
}

\author{
Nicolas X. Tritsch ${ }^{1}$ and Dwight E. Bergles ${ }^{1,2}$ \\ ${ }^{1}$ The Solomon H. Snyder Department of Neuroscience and ${ }^{2}$ Department of Otolaryngology, Head and Neck Surgery, Johns Hopkins University, Baltimore, \\ Maryland 21205
}

Neurons in the developing auditory system fire bursts of action potentials before the onset of hearing. This spontaneous activity promotes the survival and maturation of auditory neurons and the refinement of synaptic connections in auditory nuclei; however, the mechanisms responsible for initiating this activity remain uncertain. Previous studies indicate that inner supporting cells (ISCs) in the developing cochlea periodically release ATP, which depolarizes inner hair cells (IHCs), leading to bursts of action potentials in postsynaptic spiral ganglion neurons (SGNs). To determine when purinergic signaling appears in the developing cochlea and whether it is responsible for initiating auditory neuron activity throughout the prehearing period, we examined spontaneous activity from ISCs, IHCs, and SGNs in cochleae acutely isolated from rats during the first three postnatal weeks. We found that ATP was released from ISCs within the cochlea from birth until the onset of hearing, which led to periodic inward currents, $\mathrm{Ca}^{2+}$ transients, and morphological changes in these supporting cells. This spontaneous release of ATP also depolarized IHCs and triggered bursts of action potentials in SGNs for most of the postnatal prehearing period, beginning a few days after birth as IHCs became responsive to ATP, until the onset of hearing when ATP was no longer released from ISCs. When IHCs were not subject to purinergic excitation, SGNs exhibited little or no activity. These results suggest that supporting cells in the cochlea provide the primary excitatory stimulus responsible for initiating bursts of action potentials in auditory nerve fibers before the onset of hearing.

\section{Introduction}

The neural circuits responsible for processing sensory information are established early in development through a combination of genetically determined guidance events and activity-dependent refinement of synaptic connections (O'Leary et al., 2007; Huberman et al., 2008). A remarkable feature of this process is that it relies on experience-independent or "spontaneous" activity generated within sensory organs. In the visual and somatosensory systems, developing sensory organs initiate bursts of action potentials separated by long periods of quiescence in groups of neurons that share similar receptive fields (Meister et al., 1991; Khazipov et al., 2004). Similar patterns of activity have been observed in the auditory system before the onset of hearing (Lippe, 1994; Jones et al., 2007; Rodriguez-Contreras et al., 2009; Sonntag et al., 2009). This sound-independent activity is likely to originate in the cochlea (Lippe, 1994; Jones et al., 2007), and plays an important role in promoting the survival and maturation of auditory neurons (Mostafapour et al., 2000; Glueckert et al., 2003; Seal et al., 2008), development of synapses (Erazo-Fischer et al., 2007; McKay and Oleskevich, 2007), and refinement of tonotopic

\footnotetext{
Received June 26, 2009; revised Nov. 30, 2009; accepted Dec. 10, 2009.

This work was supported by National Institute on Deafness and Other Communication Disorders Grants DC008860 and DC009464, and National Institute of Neurological Disorders and Stroke Grant PAR-02-059. We thank members of the laboratory for helpful comments and discussions.

Correspondence should be addressed to Dwight E. Bergles, The Solomon H. Snyder Department of Neuroscience, Johns Hopkins School of Medicine, 725 N. Wolfe Street, WBSB 1003, Baltimore, MD 21205. E-mail: dbergles@ jhmi.edu.

DOI:10.1523/JNEUROSCI.3875-09.2010

Copyright $\odot 2010$ the authors $\quad 0270-6474 / 10 / 301539-12 \$ 15.00 / 0$
}

maps - the orderly arrangement of central auditory projections according to sound frequency (Kandler et al., 2009). Nevertheless, the period during which this activity occurs has not been defined, and the mechanisms that control the onset and cessation of this activity are mostly unknown.

Synapses between inner hair cells (IHCs) and primary afferent neurons [spiral ganglion neurons (SGNs)] in the cochlea are established embryonically (Pujol et al., 1998) and become functional almost 2 weeks before airborne sound is able to elicit neural responses in the inner ear (Beutner and Moser, 2001; Glowatzki and Fuchs, 2002). During this period, IHCs can generate $\mathrm{Ca}^{2+}$ spikes that enable transmitter release at immature ribbon synapses (Johnson et al., 2005). Previous studies have reported that IHCs in prehearing cochleae are sufficiently depolarized at rest to fire $\mathrm{Ca}^{2+}$ spikes without external input (Kros et al., 1998; Marcotti et al., 2003; Brandt et al., 2007). However, recent studies indicate that before the onset of hearing, IHCs rest below the threshold for $\mathrm{Ca}^{2+}$ spike generation, but can be depolarized by ATP released from nearby inner supporting cells (ISCs), which initiates $\mathrm{Ca}^{2+}$ spikes in IHCs and triggers discrete bursts of action potentials in SGNs (Tritsch et al., 2007). This ATP-mediated excitation synchronizes the activity of neighboring IHCs and subsides after the onset of hearing, suggesting that purinergic signaling in the cochlea also contributes to spontaneous activity in the developing auditory system. Nevertheless, the relative contribution of intrinsic $\mathrm{Ca}^{2+}$ spiking and extrinsic, ATP-mediated IHC depolarization to spontaneous auditory nerve activity remains unclear. It is also unknown whether transmitters other than ATP participate in the periodic depolarization of IHCs before hearing onset. 
Here we examine the mechanisms responsible for initiating spontaneous activity in ISCs, IHCs, and SGNs during postnatal development of the rat cochlea. Our results provide evidence that supporting cell-derived ATP constitutes the primary excitatory stimulus responsible for initiating bursts of action potentials in auditory nerve fibers before the onset of hearing.

\section{Materials and Methods}

Tissue preparation. Apical turns of prehearing [postnatal day 0 ( $\mathrm{P} 0)-\mathrm{P} 10$; day of birth is P0] and hearing (P13-P20) Sprague Dawley rat cochleae were isolated as described previously (Tritsch et al., 2007), in strict accordance with protocols approved by the Animal Care and Use Committee at Johns Hopkins University. Cochlear turns were dissected in icecold artificial CSF (ACSF) containing the following (in mM): $119 \mathrm{NaCl}$, $2.5 \mathrm{KCl}, 1.3 \mathrm{CaCl}_{2}, 1.3 \mathrm{MgCl}_{2}, 1 \mathrm{NaH}_{2} \mathrm{PO}_{4}, 26.2 \mathrm{NaHCO}_{3}$, and 11 D-glucose $\left(290 \mathrm{mmol} \cdot \mathrm{kg}^{-1}\right)$, saturated with $95 \% \mathrm{O}_{2} / 5 \% \mathrm{CO}_{2}$. Other than the stria vascularis and tectorial membrane, which were gently removed, the cellular organization of the organ of Corti was left intact to preserve intercellular signaling. Acutely isolated cochlear turns were immediately transferred to a Plexiglas chamber mounted on an upright microscope (Axioskop FS2; Zeiss) and imaged with infrared light and differential interference contrast (DIC) optics using a charge-coupled device (CCD) camera (XC-73; Sony). Preparations were held down by a flattened $\mathrm{U}$-shaped platinum wire strung with individual strands of synthetic dental floss fibers and were continually superfused $(0.5-1 \mathrm{ml} / \mathrm{min})$ with ACSF at $22-24^{\circ} \mathrm{C}$. For recordings performed at $34-36^{\circ} \mathrm{C}, \mathrm{ACSF}$ was warmed by passing it through a feedback-controlled in-line heater ( $\mathrm{SH}-$ $27 \mathrm{~B}$; Warner Instruments) before entering the chamber. In some experiments, preparations were superfused with ACSF containing $6 \mathrm{~mm} \mathrm{KCl}$; for these recordings, D-glucose was lowered to $4 \mathrm{~mm}$ to maintain a constant osmolarity.

Electrophysiology. Whole-cell voltage-clamp recordings from ISCs and IHCs were performed under visual control in the $1-6 \mathrm{kHz}$ region (Müller, 1991), as described previously (Tritsch et al., 2007). Importantly, the supporting cells of Kölliker's organ surrounding IHCs were not removed to facilitate access to IHC cell bodies. Electrodes were instead advanced through the tissue under minimal positive pressure. A newly isolated preparation was used for each recording for all pharmacological experiments and most characterizations of baseline activity. The number of recordings $(n)$ and the number of cochlear segments used for each data set are indicated below. Patch pipettes were pulled (PP-830; Narishige) from glass capillaries (PG10165-4; World Precision Instruments) and had tip resistances of 2-4 $\mathrm{M} \Omega$ when filled with an internal solution composed of the following (in mM): $134 \mathrm{KCH}_{3} \mathrm{SO}_{3}, 20 \mathrm{HEPES}, 10 \mathrm{EGTA}$, $4 \mathrm{NaCl}$, and $1 \mathrm{MgCl}_{2}$, adjusted to $\mathrm{pH} 7.3$ with $\mathrm{KOH}$ and to 290 $\mathrm{mmol} \cdot \mathrm{kg}^{-1}$ with $\mathrm{H}_{2} \mathrm{O}$. ISC recordings were limited to Kölliker's organ cells located within $30 \mu \mathrm{m}$ of IHC cell bodies at prehearing ages, and inner border and inner phalangeal cells after the onset of hearing. ISCs were voltage clamped near their membrane potential, which ranged between -50 and $-76 \mathrm{mV}$ in $\mathrm{P} 0-\mathrm{P} 2$ cochleae (mean, $-63 \pm 2 \mathrm{mV}, n=18$ ) and between -60 and $-98 \mathrm{mV}$ in P3-P20 preparations (mean, $-86 \pm 1$ $\mathrm{mV}, n=86$ ). For voltage-clamp recordings from $\mathrm{IHCs}, \mathrm{NaCl}$ was substituted with $\mathrm{Na}_{2}$ ATP $(2 \mathrm{~mm})$ and NaGTP $(0.2 \mathrm{~mm})$ to facilitate stable recordings. For current-clamp recordings from IHCs, ATP was excluded from the internal solution to minimize nucleotide-induced membrane depolarization before gigaseal formation. Pipettes had resistances of 5-9 $\mathrm{M} \Omega$. Membrane potentials were measured immediately after break-in. Extracellular field electrodes for loose-patch SGN recordings had a tip resistance of $0.7-1.5 \mathrm{M} \Omega$ when filled with ACSF, and action potentials were detected with patch resistances of 5-15 M $\Omega$. Nucleotides (ATP and UTP) dissolved in ACSF to $100 \mu \mathrm{m}$ were either puffed (100 ms, 5 psi) from a 2 - $\mu$ m-diameter pipette (see Figs. 2, 3E, $4 E, F$ ) connected to a Picospritzer (Parker Hannifin), applied via a gravity-fed $100-\mu \mathrm{m}$-wide flow pipe positioned $200 \mu \mathrm{m}$ from the recorded cell (see Fig. 6), or perfused in the bath (see Fig. 9B). The following reagents (all from Tocris Bioscience) were applied by addition to the superfusing ACSF: pyridoxal-phosphate- $2^{\prime} 4^{\prime}$-disulfonate (PPADS; $50 \mu \mathrm{M})$, suramin (100-200 $\mu \mathrm{M}$ ), and 2,3-dihydroxy-6-nitro-7sulfamoyl-benzo[f] quinoxaline-2,3-dione (NBOX; 10-20 $\mu \mathrm{M}$ ).
Data analysis. Currents and potentials were recorded with pClamp9 software using a Multiclamp 700A amplifier (Molecular Devices), lowpass filtered at $0.1-10 \mathrm{kHz}$ and digitized at $10-50 \mathrm{kHz}$ with a Digidata 1322A analog-to-digital converter (Molecular Devices). Data were analyzed off-line using Clampfit (Molecular Devices) and Origin (Microcal Software) software. Data are expressed as mean \pm SEM. Statistical tests are noted below (significance, $\alpha<0.05$ ). ANOVAs were followed with a Bonferroni's post hoc test. Voltage-clamp recordings from ISCs and IHCs were performed for 20-70 min. Spontaneous inward currents in ISCs and IHCs displaying amplitudes exceeding two times the root mean square value of baseline noise (more than $-8 \mathrm{pA}$ ), slow rise times $\left(\tau_{\text {rise }}\right.$, defined as current duration from onset to peak; $0.1-7 \mathrm{~s}$ ), and rise to decay time ratios greater than one were used for analysis. Spontaneous IHC membrane potential depolarizations with kinetics similar to inward currents and amplitudes above baseline noise $(0.9 \mathrm{mV})$ were selected for quantification. This allowed unambiguous identification of most spontaneous inward currents and depolarizations in ISCs and IHCs, while minimizing confounding factors such as electrical noise, synaptic conductances (efferents in IHCs), or baseline drift. For pharmacological analysis, the mean inward current amplitude and frequency were calculated for $200 \mathrm{~s}$ segments, normalized to baseline averages, and compared to values obtained at corresponding times in control preparations continuously bathed in ACSF. IHC currents were considered coincident when they were initiated within \pm 500 ms of one another and exhibited similar kinetics. A correlation value was obtained for each IHC pair by averaging the percent correlations obtained for both traces within a pair. Current-clamp IHC recordings were performed for 4-10 min immediately after break-in. The continued ability of IHCs to calcium spike was periodically verified by injecting small $(5-50 \mathrm{pA})$ current steps. SGN recordings lasting 15-90 min were included for analysis only if action potential firing significantly increased when IHCs were exposed to ATP (100 $\mu \mathrm{M}$; for P3-P9 SGNs) or elevated $\left[\mathrm{K}^{+}\right]_{\mathrm{e}}(30 \mathrm{~mm}$; at P0-P1), and decreased by $>90 \%$ when glutamate signaling at IHC-afferent synapses was blocked with NBQX (10-20 $\mu \mathrm{M})$ (see Fig. 9B). These criteria were adopted to ensure that SGN activity in these acutely isolated preparations arose from IHCs rather than disruption of the SGN membrane integrity by the recording electrode. Spike times and interspike intervals (ISIs) were obtained from high-pass filtered $(5 \mathrm{~Hz})$ continuous recordings using the threshold search function in Clampfit (Molecular Devices). The coefficient of variation of ISIs $\left(\mathrm{CV}_{\text {ISI }}\right)$ was computed for each cell as the ratio of ISI standard deviation over ISI mean. Intervals between action potentials of a randomly firing cell follow, by definition, an exponential probability distribution with equal mean and standard deviation. Thus, these units have $\mathrm{CV}_{\text {ISI }}$ values close to 1 . Conversely, irregularly firing units display a disproportionately large number of long intervals, which increases the ISI standard deviation compared to its mean, and therefore have $\mathrm{CV}_{\text {ISI }}$ values $>1$ (Jones et al., 2007). SGN firing was considered bursting for $\mathrm{CV}_{\text {ISI }}$ values $>2$. Individual bursts were identified as groups of four or more consecutive action potentials with interspike intervals shorter than $1 \mathrm{~s}$.

Imaging. For time-lapse imaging of ISC morphological changes, cochleae were visualized with a $40 \times$ water-immersion objective coupled to an additional $0.5-2.0 \times$ adjustable zoom lens (Zeiss) using DIC optics. Images $(\sim 220 \times 120 \mu \mathrm{m})$ were acquired at one frame per second using a frame grabber (LG-3; Scion) and Scion Image software. A newly isolated cochlea was used for each time-lapse movie. The frequency and area of spontaneous optical changes were determined from 10- to 50-min-long recordings, adjusted by subtracting frames captured at times $t_{n}$ and $t_{n+5}$ seconds using ImageJ software (NIH). Transmittance changes induced by exogenously applied nucleotides (see Fig. $4 E, F$ ) were quantified by applying a thresholding function to highlight pixels that changed their intensity (either positive or negative), and values were normalized to pixel counts before agonist application. For $\mathrm{Ca}^{2+}$ imaging, cochlear turns were incubated for 30-45 $\mathrm{min}$ at room temperature in HEPESbuffered ACSF (in mm: $130 \mathrm{NaCl}, 2.5 \mathrm{KCl}, 10$ HEPES, $1 \mathrm{NaH}_{2} \mathrm{PO}_{4}, 2.5$ $\mathrm{CaCl}_{2}, 1.3 \mathrm{MgCl}_{2}, 11 \mathrm{D}$-glucose, adjusted to $\mathrm{pH} 7.6$ with $\mathrm{NaOH}$ ) containing $2.5 \mu \mathrm{M}$ fluo-4 AM (F14201; Invitrogen), 0.01\% (w/v) pluronic acid F-127 (P3000MP; Invitrogen), and $250 \mu \mathrm{M}$ sulfinpyrazone (Sigma). Cochleae were superfused with HEPES-buffered ACSF during image acqui- 


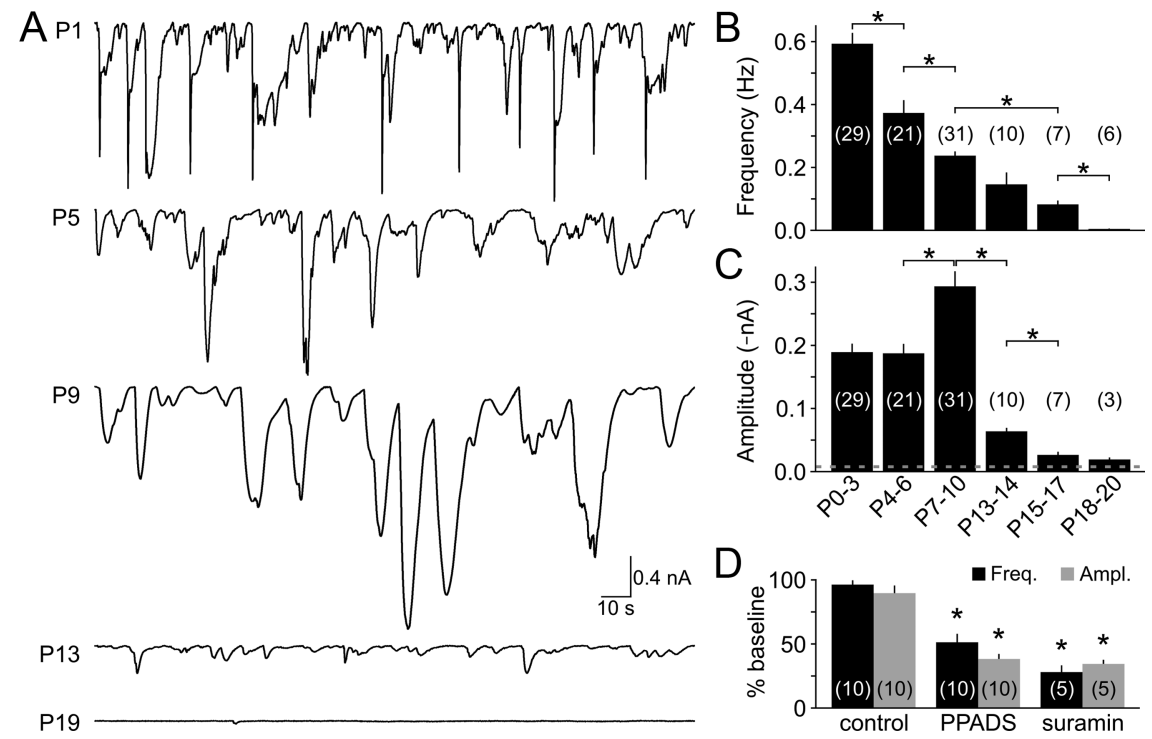

Figure 1. Spontaneous ATP-mediated inward currents in ISCS are present from birth until shortly after the onset of hearing. $\boldsymbol{A}$, Spontaneous currents recorded from ISCs at different postnatal ages. $\boldsymbol{B}, \boldsymbol{C}$, Graphs of average frequency $(\boldsymbol{B})$ and amplitude $(\boldsymbol{C})$ of spontaneous inward currents at different postnatal ages. Dashed line indicates the detection threshold for inward currents $(-8$ pA). Recordings (indicated in parentheses) were obtained from 3 to 26 cochleae per age group. ${ }^{*} p<0.001$ for indicated pairs (two-sample $t$ test). $\boldsymbol{D}$, Average spontaneous inward current amplitude (gray) and frequency (black) recorded from $\mathrm{P} 0-\mathrm{P} 3$ cochleae under control conditions, in PPADS $(50 \mu \mathrm{m})$ or suramin $(100-150 \mu \mathrm{M})$. Each recording (indicated in parentheses) was performed in a newly isolated cochlea. ${ }^{*} p<0.0001$ versus control (two-sample $t$ test). Error bars in $\boldsymbol{B}-\boldsymbol{D}$ indicate SEM.
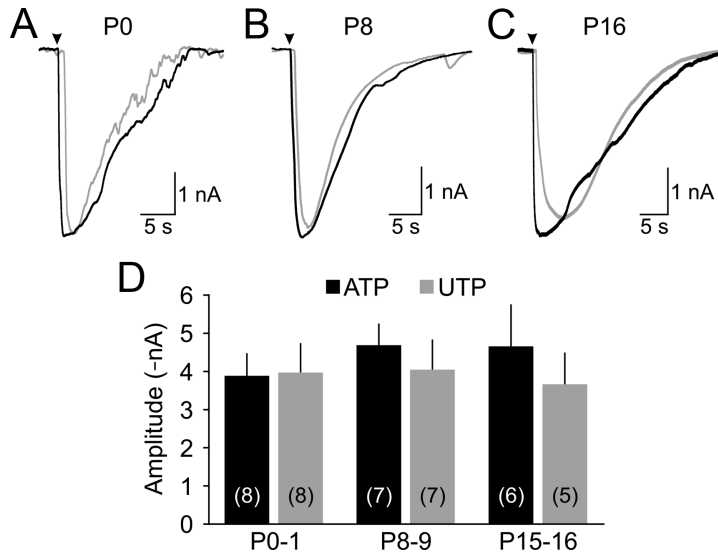

Figure 2. Cochlear supporting cells remain responsive to ATP throughout early development. $\boldsymbol{A}-\boldsymbol{C}$, Representative inward currents elicited by local application (arrowhead) of ATP (100 $\mu \mathrm{m}$; black traces) or UTP (100 $\mu \mathrm{m}$; gray traces) to inner supporting cells in P0 (A), P8 (B), and P16 (C) cochleae. $\boldsymbol{D}$, Graphs of average current amplitude ( \pm SEM) evoked by ATP (black) or UTP (gray) at different postnatal ages. The number of experiments is indicated in parentheses.

sition. Fluorescence images $(\sim 200 \times 100 \mu \mathrm{m})$ were collected every $0.8-1 \mathrm{~s}$ for 5-30 min with a laser scanning confocal microscope (LSM 510; Zeiss) using a $40 \times$ water-immersion objective, $488 \mathrm{~nm}$ laser illumination, and $500-530 \mathrm{~nm}$ bandpass filter. Simultaneous DIC imaging was performed by collecting light that passed through the sample with a photomultiplier tube. The frequency and area of spontaneous $\mathrm{Ca}^{2+}$ transients were measured using ImageJ. The frequencies of spontaneous optical changes and $\mathrm{Ca}^{2+}$ transients were normalized for a $10^{4} \mu \mathrm{m}^{2}$ imaging area to account for age-dependent changes in the size of Kölliker's organ/inner sulcus.

\section{Results}

Developmental changes in spontaneous electrical activity in cochlear supporting cells

The developing cochlea of mammals contains a cluster of columnar-shaped ISCs that form a structure known as Kölliker's organ, which is located immediately medial to inner hair cells (Hinojosa, 1977; Kelley, 2007). Spontaneous release of ATP from one or more ISCs triggers activation of purinergic (P2) receptors in these and neighboring ISCs, leading to inward currents, a rise in intracellular $\mathrm{Ca}^{2+}$, and crenation (Tritsch et al., 2007). To determine when during postnatal development ISCs exhibit this ATP-mediated activity, we made whole-cell voltage-clamp recordings from ISCs in cochleae acutely isolated before the onset of hearing, which in rats begins at about P11 (Ehret, 1983). Spontaneous inward currents were observed in ISCs at all prehearing ages $(n=81)$, although the amplitude, kinetics, and frequency of these events varied with development (Fig. $1 A-C$ ). At early prehearing ages ( $\mathrm{P} 0-\mathrm{P} 3)$ the currents were smaller (mean amplitude, $-189 \pm 14 \mathrm{pA}$; range, -8 to $-5501 \mathrm{pA})$, faster (rise time $\left(t_{\text {rise }}\right)$, $537 \pm 25 \mathrm{~ms})$, and more frequent $(0.59 \pm$ $0.04 \mathrm{~Hz} ; n=29)$ than currents recorded close to the onset of hearing (P7-P10; amplitude, $-293 \pm 24 \mathrm{pA}$; range, -8 to $-5986 \mathrm{pA}, p<0.001 ; t_{\text {rise }}=1,445 \pm 53$ $\mathrm{ms}, p<0.001$; frequency, $0.24 \pm 0.01 \mathrm{~Hz}$, $n=31, p<0.001$, two-sample $t$ test). Despite these differences, currents at both stages of development were significantly inhibited by the P2 purinergic receptor antagonists PPADS $(50 \mu \mathrm{M})$ and suramin $(100-150 \mu \mathrm{M})$ (Fig. $1 D$; supplemental Fig. 1, available at http://www.jneurosci.org/ as supplemental material). Moreover, focal application of either ATP or UTP, a P2Y receptor-specific agonist, elicited large inward currents at both early and late prehearing stages ( $p=0.8$, ANOVA) (Fig. $2 A, B, D)$, although the onset of UTP-evoked responses was delayed relative to those elicited by ATP (mean difference, $502 \pm 32 \mathrm{~ms} ; n=23$; $p<0.001$, paired $t$ test), as expected for responses that depend on second messenger generation. Supporting cells in the developing cochlea are extensively coupled via gap junctions (Jagger and Forge, 2006). As a result, ATP-evoked currents propagate electrotonically throughout Kölliker's organ and can be recorded several millimeters from where they are generated (N. X. Tritsch and D. E. Bergles, unpublished observations). Differences in the amplitude and kinetics of spontaneous ATP-induced currents during the first 10 postnatal days may therefore result from changes in electrical coupling between ISCs, the location of ATP release, the amount of ATP released by ISCs, or the properties of purinergic receptors expressed. Together, these results indicate that ISCs in the developing cochlea express both ionotropic and metabotropic purinergic receptors and respond to the spontaneous release of ATP with inward currents throughout the postnatal prehearing period.

After the onset of hearing, ISCs exhibited greatly reduced electrical activity (Fig. 1A-C); spontaneous inward currents occurred infrequently $(0.08 \pm 0.01 \mathrm{~Hz})$ and were smaller at P15$\mathrm{P} 17$ ( $-26 \pm 5 \mathrm{pA}, n=7, p<0.001$ vs P7-P10, two-sample $t$ test), and mostly absent by $\mathrm{P} 18-\mathrm{P} 20(n=6)$. This rapid decline in activity could result from reduced expression of purinergic receptors or cessation of spontaneous ATP release. Both ATP and UTP elicited inward currents in ISCs in P15-P16 cochleae $(n=11)$ that were comparable to those elicited in prehearing cochleae 
$(p=0.9$, ANOVA) (Fig. $2 C, D)$, suggesting that the abrupt decrease in spontaneous currents after the onset of hearing is attributable to a reduction in ATP release rather than a down regulation of purinergic receptors in ISCs.

\section{Developmental regulation of spontaneous $\mathrm{Ca}^{2+}$ transients in supporting cells}

To determine whether the electrical activity exhibited by ISCs is associated with intracellular $\mathrm{Ca}^{2+}$ transients, we monitored $\mathrm{Ca}^{2+}$ levels in acutely isolated cochleae using the fluorescent $\mathrm{Ca}^{2+}$ indicator fluo-4. In agreement with observations made in organotypic preparations (Tritsch et al., 2007), spontaneous $\mathrm{Ca}^{2+}$ elevations were observed within ISCs of Kölliker's organ in all cochleae acutely isolated before the onset of hearing ( $n=$ 24) (Fig. $3 A$; supplemental Movie 1 , available at http://www.jneurosci.org/ as supplemental material). These $\mathrm{Ca}^{2+}$ transients became more prominent with age, with the frequency and mean area increasing by 5.1 - and 1.7-fold, respectively, from early prehearing to late prehearing stages $(p<0.001$ and $p=0.001$, twosample $t$ tests) (Fig. $3 B, C$ ). PPADS (50 $\mu \mathrm{M})$ and suramin $(150 \mu \mathrm{M})$ significantly decreased the incidence of these transients at both ages (Fig. 3D), indicating that spontaneous elevations of intracellular $\mathrm{Ca}^{2+}$ in ISCs are induced by extracellular ATP from birth until hearing onset. Despite the high incidence of ATP-mediated currents at early postnatal ages (Fig. 1), the frequency of spontaneous $\mathrm{Ca}^{2+}$ transients was comparatively low in $\mathrm{P} 0-\mathrm{P} 1$ cochleae. It is possible that the amounts of ATP released during this period may be too small to reliably elicit $\mathrm{Ca}^{2+}$ transients, as exogenous ATP $(100 \mu \mathrm{M})$ evoked robust $\mathrm{Ca}^{2+}$ signals in Kölliker's organ at these ages $\left(\Delta F / F_{0}=230 \pm 14 \%, n=9\right)$ (Fig. 3E).

Exogenous ATP was able to elevate intracellular $\mathrm{Ca}^{2+}$ in ISCs after the onset of hearing $\left(\Delta F / F_{0}=87 \pm 9 \%, n=4\right)$ (Fig. $3 E)$, yet only one spontaneous $\mathrm{Ca}^{2+}$ transient (area, $324 \mu \mathrm{m}^{2}$ ) was observed in six P16 cochleae (Fig. $3 B$ ). These results indicate that spontaneous $\mathrm{Ca}^{2+}$ transients are induced in ISCs by ATP throughout the postnatal prehearing period, and that these events rapidly disappear after the onset of hearing despite the continued expression of purinergic receptors.

Spontaneous ATP-dependent $\mathrm{Ca}^{2+}$ transients first appeared in single ISCs or small clusters of ISCs and then propagated radially within Kölliker's organ without directional bias. Although $\mathrm{Ca}^{2+}$ transients also can be elicited in other supporting cells such as Deiters' cells and Hensen's cells in response to mechanical stimulation or ATP (Gale et al., 2004; Piazza et al., 2007; Tritsch et

B
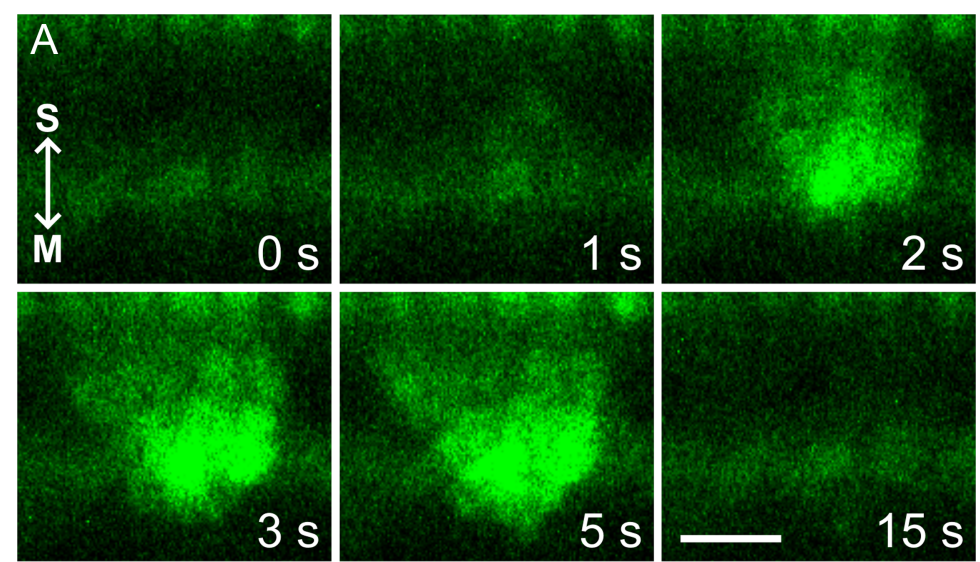

C
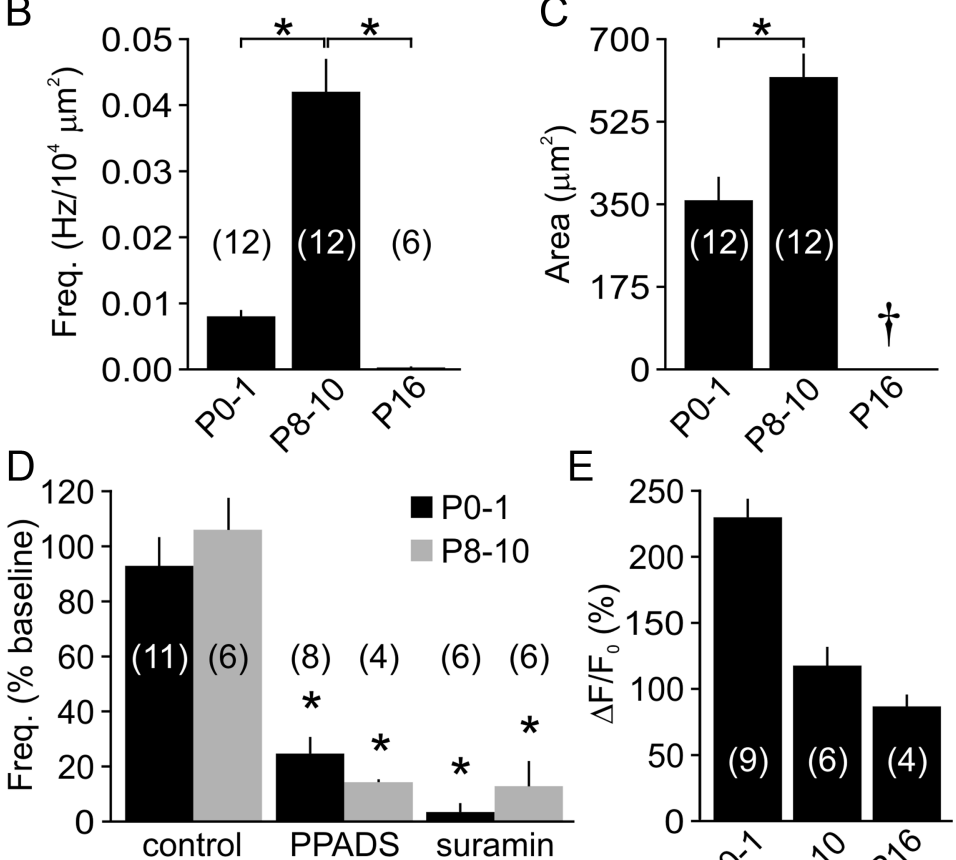

E

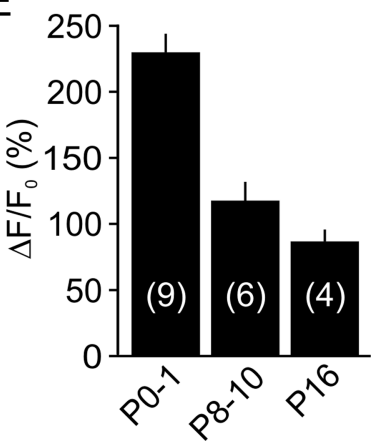

Figure 3. Developmental changes in spontaneous $\mathrm{Ca}^{2+}$ transients in Kölliker's organ supporting cells. $\boldsymbol{A}$, Time lapse recording showing a spontaneous intracellular $\mathrm{Ca}^{2+}$ transient (fluo-4 fluorescence) within the supporting cells of Kölliker's organ (age, P10). Arrows point to the modiolus (M) and stria vascularis (S) for orientation. Scale bar, $20 \mu \mathrm{m} . \boldsymbol{B}, \boldsymbol{C}$, Graphs of average frequency $(\boldsymbol{B})$ and area $(\boldsymbol{C})$ of spontaneous $\mathrm{Ca}^{2+}$ transients at different postnatal ages. Only one event (324 $\mu \mathrm{m}^{2}$ ) was detected in six cochleae at P16 (dagger). ${ }^{*} p<0.002$ for indicated pairs (two-sample $t$ test). D, Graph of average frequency of spontaneous $\mathrm{Ca}^{2+}$ transients within Kölliker's organ under control conditions, or in the presence of control (two-sample $t$ test). $\boldsymbol{E}$, Histogram of average changes in fluo-4 fluorescence (normalized to baseline $\left(\Delta F / F_{0}\right)$ ) within inner supporting cells after local application of ATP $(100 \mu \mathrm{M})$ at different postnatal ages. Data in $\boldsymbol{B}-\boldsymbol{E}$ are expressed as mean \pm SEM. In $\boldsymbol{B}$ and $\boldsymbol{D}$, values were normalized for the area of Kölliker's organ/inner sulcus imaged. The number of cochleae is indicated in parentheses.

al., 2007), spontaneous $\mathrm{Ca}^{2+}$ transients were not observed in these cells at any prehearing age $(n=11)$. These results suggest that ATP is released spontaneously only from Kölliker's organ in the developing organ of Corti, and that this transmitter does not reach the outer sulcus at a concentration sufficient to induce a substantial elevation of intracellular $\mathrm{Ca}^{2+}$ in other classes of supporting cells.

\section{Developmental regulation of ATP-induced crenation of supporting cells}

Purinergic receptor activation also induces dramatic changes in the shape of ISCs, which transiently shrink or crenate fol- 


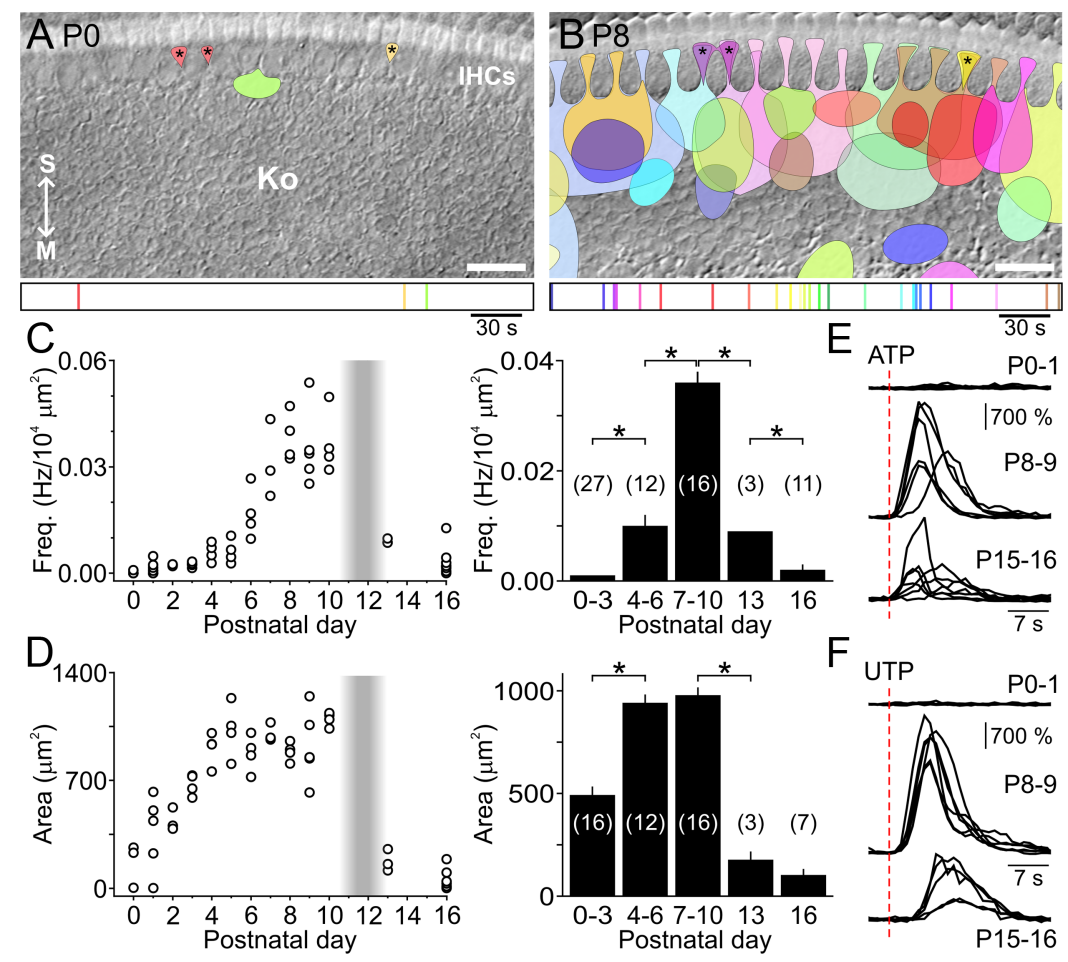

Figure 4. Supporting cells develop the ability to crenate during the first postnatal week. $\boldsymbol{A}, \boldsymbol{B}$, Location and size of individual spontaneous optical changes within Kölliker's organ (Ko) during 300 s sample periods at P0 (A) and P8 $(\boldsymbol{B})$. Asterisks indicate brief ATP-independent transients limited to the processes of inner phalangeal and inner border cells that were excluded from analyses (see Results). Arrows point to the modiolus (M) and stria vascularis (S) for orientation. Scale bar, $20 \mu \mathrm{m}$. Bottom, Time of occurrence of individual spontaneous optical changes, color-coded according to time of occurrence. $\boldsymbol{C}, \boldsymbol{D}$, Left, Graphs of average frequency ( $\boldsymbol{C}$, normalized for area of Kölliker's organ/inner sulcus imaged) and average area $(\boldsymbol{D})$ of spontaneous optical changes imaged from individual cochleae at various postnatal ages $(n=3-14$ cochleae per age). The shaded vertical bar indicates the period when rats become sensitive to airborne sounds. Preparations in which spontaneous optical changes were not observed were assigned a mean area of $0 \mu \mathrm{m}^{2}$ in $\boldsymbol{D}$. Right, Histograms of average ( \pm SEM) frequency $(\boldsymbol{C})$ and area $(\boldsymbol{D})$ of spontaneous optical changes for indicated age groups. Preparations without spontaneous optical changes were included in calculations of average frequency in $C$, but not in calculations of average area in $\boldsymbol{D}$. The number of cochleae is indicated in parentheses. ${ }^{*} p<0.002$ for indicated pairs (two-sample $t$ test). $\boldsymbol{E}, \boldsymbol{F}$, Normalized changes in light transmittance evoked by local application (red dashed lines) of ATP (100 $\mu \mathrm{M}, \boldsymbol{E})$ or UTP $(100 \mu \mathrm{m}, \boldsymbol{F})$ at indicated postnatal ages ( $n=5-7$ cochleae per age group).

lowing exposure to ATP (Tritsch et al., 2007). Such spontaneous morphological changes occurred in ISCs within Kölliker's organ and in the processes of inner border and inner phalangeal cells in all P7-P10 cochleae $(n=16)$ at a frequency of $0.036 \pm 0.002 \mathrm{~Hz} / 10^{4} \mu \mathrm{m}^{2}$ (Fig. 4 B, C; supplemental Movie 2, available at http://www.jneurosci.org/ as supplemental material). Crenation first appeared in a small cluster of ISCs before expanding radially to encompass an average area of $973 \pm 39$ $\mu \mathrm{m}^{2}$ (range, $120-7380 \mu \mathrm{m}^{2}$ ). These events appeared in apparent random locations along the tonotopic axis, but were biased toward inner hair cells along the modiolar-to-strial axis (Fig. $4 \mathrm{~B}$ ). Despite evidence indicating that ATP is released throughout the first 2 postnatal weeks (Figs. 1, 3), spontaneous morphological changes were detected in only $45 \%$ of P0-P1 cochleae $(n=9 / 20)$, and when present, they occurred infrequently $(0.0018 \pm 0.0005$ $\mathrm{Hz} / 10^{4} \mu \mathrm{m}^{2} ; n=9 ; p<0.001$, two-sample $t$ test) and were smaller in area $\left(424 \pm 55 \mathrm{\mu m}^{2} ; p<0.001\right.$, two-sample $t$ test) compared to events in late prehearing cochleae (Fig. $4 A, C, D$; supplemental Movie 2, available at http://www.jneurosci.org/ as supplemental material), in agreement with the developmental time course of spontaneous $\mathrm{Ca}^{2+}$ transients. However, decreased purinergic signaling alone cannot account for the delayed onset of these morphological changes, as both ATP and UTP elicited large inward currents (Fig. 2) and elevated intracellular $\mathrm{Ca}^{2+}$ in P0-P1 ISCs (Fig. $3 E)$, but did not elicit crenation $(n=7)$ (Fig. $4 E, F$ ). These results suggest that the cellular machinery required for crenation matures after supporting cells begin to release ATP.

Spontaneous morphological changes were also rare after the onset of hearing. By P16, only $64 \%$ of cochleae exhibited crenation events $(n=11)$, and both the frequency and amplitude of these events were reduced relative to the late prehearing period $(p<0.001$ for both, twosample $t$ test) (Fig. 4C,D). Both ATP and UTP were able to induce crenation of ISCs after the onset of hearing (Fig. $4 E, F$ ), indicating that the decrease in incidence of these spontaneous morphological changes is primarily caused by a reduction in the frequency of ATP release events.

Analysis of time-lapse movies also revealed the existence of intrinsic optical changes distinct from ATP-mediated crenation of ISCs (Fig. 4A, $B$, asterisks; supplemental Movie 2, available at http://www.jneurosci.org/ as supplemental material). These events were brief (typically seen in only a few frames) and small $\left(20-150 \mu \mathrm{m}^{2}\right)$, and occurred in the processes of one to three adjacent inner phalangeal and inner border cells at a frequency of $0.0024 \pm 0.0003 \mathrm{~Hz}(n=35$ cochleae) at all ages studied. They coincided with brief intracellular $\mathrm{Ca}^{2+}$ transients confined to the distal processes of inner phalangeal and inner border cells (data not shown). These events were not affected by PPADS $(n=11 ; p=0.15$, paired $t$ test $)$ or suramin $(n=6 ; p=0.11$, paired $t$ test), suggesting that they are intrinsically generated, perhaps through spontaneous release of $\mathrm{Ca}^{2+}$ from internal stores. These events were not included in additional analyses.

Developmental changes in ATP-dependent excitation of IHCs ATP that is released from ISCs can also reach IHCs at concentrations sufficient to activate purinergic receptors and elicit inward currents (Tritsch et al., 2007). To determine when during development IHCs are subjected to purinergic excitation, we made whole-cell voltage-clamp recordings from IHCs at a range of postnatal ages. Although the recordings from ISCs indicated that ATP is released at birth (Figs. 1, 3), spontaneous inward currents were not detected in IHCs at P0 $(n=$ 4 ), and were present in only $47 \%$ of IHCs between P1 and P3 $(n=17)$ (Fig. 5A-C). By P4, spontaneous inward currents were consistently seen in all IHCs, and the amplitude and frequency of these events progressively increased with age until the onset of hearing (Fig. 5A-C). Just after the onset of hearing (P15P17), spontaneous currents were observed in only $56 \%$ of IHCs $(n=9)$, and the amplitude and frequency were significantly reduced relative to the level of activity just before hearing onset ( $p<0.001$ for both, two-sample $t$ test) (Fig. 5A-C). To determine whether these developmental changes in IHC 

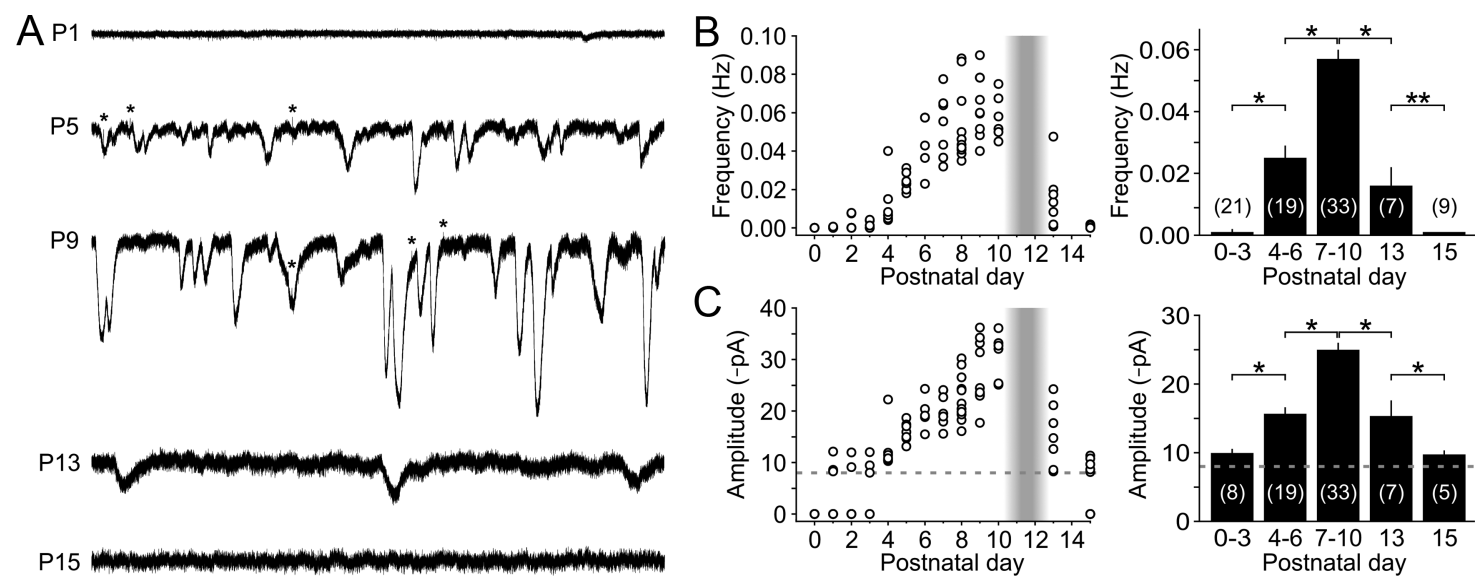

Figure 5. Spontaneous inward currents in $\mathrm{IHCs}$ emerge early in postnatal development and persist until the onset of hearing. $A$, Spontaneous inward currents recorded from $\mathrm{IHCs}\left(V_{\mathrm{h}}=-80 \mathrm{mV}\right)$ at indicated postnatal ages. Asterisks indicate spontaneous efferent-induced biphasic currents. $\boldsymbol{B}, \boldsymbol{C}$, Left, Graphs of average frequency $(\boldsymbol{B})$ and amplitude $(\boldsymbol{C})$ of spontaneous inward currents recorded from IHCs from ages P0 to P15 ( $n=4-11$ IHCs in 4-9 cochleae per age). Shaded vertical bar highlights the period of hearing onset. Dashed line indicates the detection threshold ( $-8 \mathrm{pA}$ ). IHCs in which spontaneous inward currents were not recorded were assigned a mean amplitude of $0 \mathrm{pA}$ in $\boldsymbol{C}$ for display purposes. Right, Histograms of average ( \pm SEM) frequency $(\boldsymbol{B})$ and amplitude $(\boldsymbol{C})$ of spontaneous inward currents recorded from IHCs at different ages. IHCs without spontaneous inward currents were included for calculations of average frequency $(\boldsymbol{B})$, but not average amplitude $(\boldsymbol{C})$. The number of recordings is indicated in parentheses. ${ }^{*} p<0.005 ;{ }^{* *} p<0.05$ (tw0-sample $t$ test).

activity correspond to changes in purinergic receptor expression, we measured the response of IHCs to focal application of ATP $(100 \mu \mathrm{M})$. ATP reliably evoked inward currents in all IHCs between $\mathrm{P} 7$ and $\mathrm{P} 10$ (mean, $-135 \pm 10$ $\mathrm{pA} ; n=13)$, but elicited little or no response at $\mathrm{P} 0$ (mean, $-5.6 \pm 0.8 \mathrm{pA} ; n=$ $4 ; p<0.001$, two-sample $t$ test) (Fig. $6 A-C)$. The amplitudes of ATP-evoked responses increased progressively from $\mathrm{P} 1$ until the end of the first postnatal week, then remained stable until just after hearing onset when they rapidly declined. These results indicate that IHCs are responsive to extracellular ATP only during a limited period of postnatal development beginning between $\mathrm{P} 1$ and $\mathrm{P} 4$ and end shortly after the onset of hearing.

IHCs that lie in close physical proximity to one another are more likely to exhibit similar patterns of activity than IHCs located farther apart (Tritsch et al., 2007), because they will be exposed to similar concentrations of ATP. To determine whether ATP can synchronize the activity of neighboring hair cells when endogenous ATP-evoked currents first appear, we performed simultaneous whole-cell voltage-clamp recordings from pairs of IHCs located 58-322 $\mu \mathrm{m}$ apart in $\mathrm{P} 4-\mathrm{P} 6$ cochleae (Fig. 7A). A larger proportion of spontaneous inward currents were correlated in IHCs within $100 \mu \mathrm{m}$ of each other ( $83 \pm 2 \% ; n=7$ pairs) compared to cells separated by distances $>200 \mu \mathrm{m}(28 \pm 3 \% ; n=7$ pairs; $p<$ 0.001, ANOVA) (Fig. $7 B, C$ ). Notably, the ability of extracellular ATP to synchronize IHCs did not change noticeably with age, as correlations between inward currents recorded from pairs in P4-P6 and P7-P10 cochleae were not statistically significant, regardless of the distance separating IHCs (Fig. $7 B, C$ ). These results indicate that purinergic signaling efficiently synchronizes the activity of IHCs as soon as IHCs become responsive to ATP until the onset of hearing.
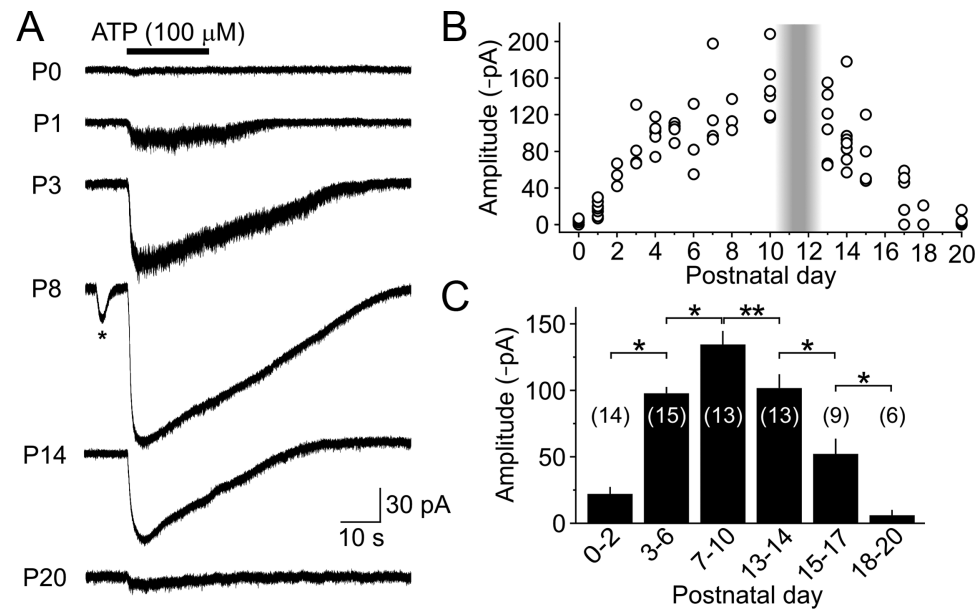

Figure 6. IHCs are responsive to ATP during a restricted period of development. $A$, Whole-cell voltage-clamp recordings $\left(V_{\mathrm{h}}=\right.$ $-80 \mathrm{mV}$ ) of currents induced in IHCs by local application of ATP. Asterisk highlights a spontaneous inward current. $\boldsymbol{B}$, Graph of the maximum amplitude of ATP-evoked inward currents recorded from IHCs at different postnatal ages ( $n=2-7 \mathrm{IHCs}$ per age). The shaded vertical bar highlights the period of hearing onset. $C$, Histogram of average ( \pm SEM) amplitude of ATP-induced currents recorded from IHCs at different ages. The number of $\mathrm{IHC}$ is indicated in parentheses. ${ }^{*} p<0.005 ;{ }^{* *} p<0.05$ (two-sample $t$ test).

\section{Temperature dependence of spontaneous purinergic signaling}

To confirm that spontaneous purinergic signaling persists at physiological temperatures, we recorded spontaneous inward currents in ISCs and IHCs and monitored spontaneous morphological changes in P7-P10 preparations perfused with ACSF warmed to $34-36^{\circ} \mathrm{C}$. Elevating the temperature to near-physiological levels increased the frequency of spontaneous inward currents in both ISCs and IHCs by $2.2-$ and 2.3 -fold, respectively $(p<0.0001)$, and decreased their rise times by 1.9- and 1.7-fold ( $p<0.0001)$, but did not alter their mean amplitudes $(p>0.08$, two-sample $t$ test $)$ (supplemental Fig. 2, available at http://www.jneurosci.org/ as supplemental material). Elevated temperatures similarly increased the occurrence of morphological changes in Kölliker's organ supporting cells by 1.6-fold ( $p<0.0003$, two-sample $t$ test), although their mean area was unchanged ( $p=0.12$, twosample $t$ test). These results indicate that the frequency, but not 


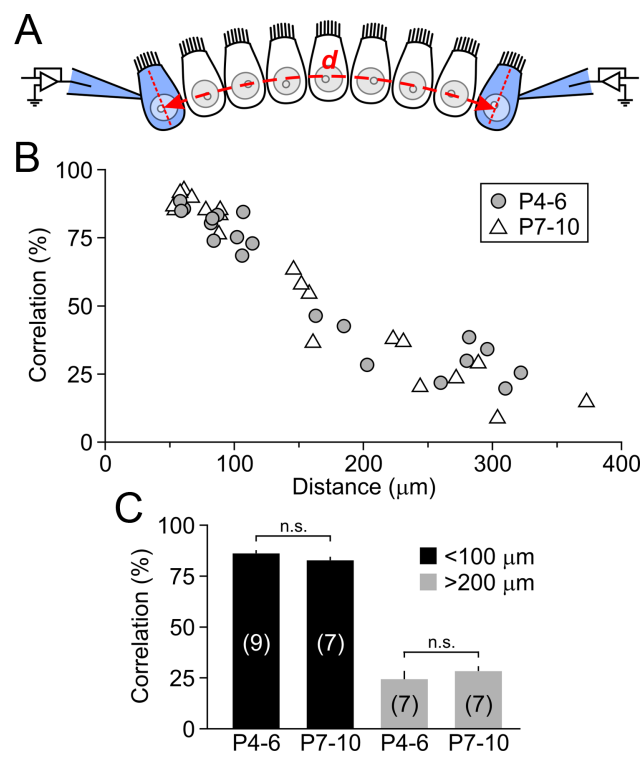

Figure 7. Synchrony of spontaneous inward currents between IHCs does not change with development. $\boldsymbol{A}$, Schematic of recording configuration. Spontaneous inward currents were recorded simultaneously from two whole-cell voltage-clamped IHCs (indicated in blue, $V_{\mathrm{h}}=$ $-80 \mathrm{mV}$ ) separated by distance $d$ (measured by taking into account the curvature of the cochlea). $\boldsymbol{B}$, Scatter plot of spontaneous inward current correlation for individual IHC pairs in P4-P6 (gray circles) and P7-P10 (white triangles) cochleae as a function of distance $d$. C, Histogram of spontaneous inward current correlation for all IHC pairs separated by $<100 \mu \mathrm{m}$ (black bars) or distances $>200 \mu \mathrm{m}$ (gray bars) at P4 -P6 (12 cochleae) and P7-P10 (11 c0(hleae). The number of paired recordings is indicated in parentheses. n.s., Not significant (ANOVA).

the magnitude, of ATP release events from supporting cells increases with temperature.

\section{Initiation of spontaneous $\mathrm{Ca}^{2+}$ spikes in IHCs during development}

IHCs fire regenerative $\mathrm{Ca}^{2+}$ spikes in response to depolarization only during the prehearing period (Kros et al., 1998; Marcotti et al., 2003; Brandt et al., 2007). The large intracellular $\mathrm{Ca}^{2+}$ transients that occur during these spikes may facilitate transmitter release from immature ribbon synapses, which exhibit a lower sensitivity to intracellular $\mathrm{Ca}^{2+}$ before hearing onset (Beutner and Moser, 2001; Johnson et al., 2005). To determine when during development ATP release from ISCs triggers $\mathrm{Ca}^{2+}$ spikes, we recorded evoked and spontaneous activity from IHCs in the current-clamp configuration. In accordance with previous findings (Kros et al., 1998; Marcotti et al., 2003; Brandt et al., 2007), injection of depolarizing current elicited $\mathrm{Ca}^{2+}$ spikes in all IHCs between the ages of $\mathrm{P} 0$ and $\mathrm{P} 9(n=59)$ (Fig. $8 A$ ), indicating that excitability is established at or before birth. The height of evoked $\mathrm{Ca}^{2+}$ spikes, measured as the difference between the peak and the minimum membrane potential achieved after the spike was $44.8 \pm 0.3 \mathrm{mV}\left(n=868 \mathrm{Ca}^{2+}\right.$ spikes $)$, and the half-maximal width averaged $98.9 \pm 3.7 \mathrm{~ms}$ in P0-P2 IHCs ( $n=192$ spikes) and $26.7 \pm 0.8 \mathrm{~ms}$ at $\mathrm{P} 4-\mathrm{P} 9(n=676$ spikes $)$. Evoked $\mathrm{Ca}^{2+}$ spikes occurred at a frequency of $0.5-2 \mathrm{~Hz}$ near the threshold for spike initiation and increased to a maximum of $16 \mathrm{~Hz}$ (mean, $10.4 \pm$ $0.5 \mathrm{~Hz} ; n=35$ ) in response to injection of larger currents. However, the resting membrane potential of IHCs at all prehearing ages (supplemental Fig. 3, available at http://www.jneurosci.org/ as supplemental material) was below the $\mathrm{Ca}^{2+}$ spike threshold (P0-P2 IHCs, $-54.4 \pm 0.5 \mathrm{mV}, n=21$; P4-P9 IHCs, $-48.7 \pm$ $0.4 \mathrm{mV}, n=20$ ) in extracellular solution containing either 2.5
$\mathrm{mM} \mathrm{K}^{+}$, which is similar to the $\mathrm{K}^{+}$composition of perilymph in the organ of Corti in vivo (Anniko and Wroblewski, 1986), or 6 $\mathrm{mM} \mathrm{K} \mathrm{K}^{+}$, a concentration commonly used for in vitro cochlear recordings, suggesting that IHCs require external input to initiate firing before hearing onset. In keeping with the low sensitivity of early postnatal IHCs to ATP (Figs. 5, 6), most IHCs between the ages of P0 and P2 (21 of 24 cells, 88\%) were electrically silent (Fig. $8 \mathrm{~B})$. Of the three IHCs that displayed spontaneous activity, one (P1) fired a few $\mathrm{Ca}^{2+}$ spikes at very low frequency $(0.04 \mathrm{~Hz})$ throughout the recording, and two (P0 and $\mathrm{P} 2)$ fired $\mathrm{Ca}^{2+}$ spikes at a frequency of $0.5-1.0 \mathrm{~Hz}$ during the first $\sim 50 \mathrm{~s}$ following establishment of the whole-cell recording configuration, before they settled to more negative membrane potentials and ceased firing. Beginning at P3, IHCs displayed spontaneous slow depolarizations $\left(\tau_{\text {rise }}=2,518 \pm 111 \mathrm{~ms} ; n=35\right)$ of 0.9 to 15.5 $\mathrm{mV}$ (mean, $2.8 \pm 0.2 \mathrm{mV}$ ) that occurred at a frequency of $0.020 \pm 0.003 \mathrm{~Hz}$ at P3-P6 $(n=23)$ and $0.050 \pm 0.005 \mathrm{~Hz}$ at P8-P9 $(n=12)$. Larger depolarizing events triggered $\mathrm{Ca}^{2+}$ spikes that occurred at $3.5 \pm 0.3 \mathrm{~Hz}$ within each burst (Fig. $8 B$ ). These data suggest that most IHCs are not intrinsically active before the onset of hearing, and rely on external input in the form of extracellular ATP from supporting cells to initiate $\mathrm{Ca}^{2+}$ spikes.

\section{Developmental regulation of auditory nerve firing before hearing onset}

SGNs are solely responsible for conveying hair cell activity to auditory centers of the brain. To determine the patterns of activity exhibited by SGNs during the prehearing period, we recorded extracellular action potentials from the cell bodies of individual SGNs using the loose-patch method. In accordance with the low rates of spontaneous activity exhibited by IHCs in $\mathrm{P} 0-\mathrm{P} 1$ cochleae, the mean firing rates of SGNs at this age were very low in four of six cells $(0.013 \pm 0.009 \mathrm{~Hz} ; n=4)$ (Fig. 9A-C), and in two cells spontaneous action potentials were not observed. Nevertheless, elevation of extracellular $\mathrm{K}^{+}$from 6 to $30 \mathrm{~mm}$ triggered a train of action potentials in all SGNs at this age, which was reduced $98 \pm 1 \%$ by NBQX $(10-20 \mu \mathrm{M} ; n=6$; $p<$ 0.001 , one-sample $t$ test), indicating that IHC ribbon terminals are functional in newborn IHCs and that depolarizationevoked glutamate exocytosis can trigger action potentials in auditory afferents as early as P0.

The patterns of activity exhibited by SGNs between P3 and P5 were heterogeneous, consisting of discrete bursts of action potentials separated by long periods of silence in some cells and randomly spaced action potentials in others. In all cells, both spontaneous and ATP-evoked activity was reduced $99 \pm 1 \%$ by NBQX $(10-20 \mu \mathrm{M} ; n=17 ; p<0.001$, one-sample $t$ test $)$, indicating that all activity originated from IHCs. These results suggest that between the ages of P3 and P5, some IHCs are sufficiently depolarized to initiate tonic, low-frequency firing in SGNs, whereas others require external input to reach $\mathrm{Ca}^{2+}$ spike threshold. To characterize the discharge pattern of individual SGNs, we calculated the $\mathrm{CV}_{\text {ISI }}$, which serves as a measure of discharge variability. Whereas randomly firing units have $\mathrm{CV}_{\text {ISI }}$ values close to 1 , bursting units typically display $\mathrm{CV}_{\text {ISI }}$ values $>1$ (Jones et al., 2007). The pattern of activity exhibited by SGNs shifted from random firing at $\mathrm{P} 3\left(\mathrm{CV}_{\mathrm{ISI}}=1.2 \pm 0.1 ; n=4\right)$ to burst firing at $\mathrm{P} 5$ $\left(\mathrm{CV}_{\text {ISI }}=3.2 \pm 0.5 ; n=7 ; p=0.005\right.$, two-sample $t$ test) (Fig. 9E). This time period coincides with the onset of ATP-mediated inward currents in IHCs (Fig. 5), suggesting that spontaneous purinergic signaling in IHCs mediates the transition to burst firing. Consistent with this hypothesis, suramin (150-200 $\mu \mathrm{M})$ reduced 
the mean firing rate of P4-P5 SGNs by $90 \pm 5 \%(n=6 ; p<0.001$, one-sample $t$ test). In P8-P9 cochleae, all SGNs exhibited spontaneous bouts of intense firing separated by long periods of quiescence (Fig. 9A,B), similar to the activity observed in SGNs in cochleae maintained in culture (Tritsch et al., 2007) and in the auditory nerve of prehearing cats in vivo (Jones et al., 2007). Action potential bursts lasted for $4.2 \pm 0.2 \mathrm{~s}(n=362$ bursts) and occurred at a frequency of $0.031 \pm 0.005 \mathrm{~Hz}(n=8)$. SGNs at these ages exhibited low mean firing rates $(1.5 \pm 0.2 \mathrm{~Hz} ; n=8)$ (Fig. 9C) and large $\mathrm{CV}_{\text {ISI }}$ values (mean, $5.2 \pm 0.3$ ) (Fig. 9E), consistent with the grouping of action potentials into discrete clusters. The discharge rate between bursts was $0.08 \pm 0.02$ $\mathrm{Hz}(n=8)$ and increased significantly during bursts $(14.7 \pm 3.7 \mathrm{~Hz} ; p=0.005$, two-sample $t$ test), reaching instantaneous values as high as $358 \mathrm{~Hz}$ (Fig. 9D). The frequency of these spontaneous action potentials was also reduced $98 \pm 1 \%$ by NBQX $(10-20 \mu \mathrm{M} ; n=8 ; p<0.001$, one-sample $t$ test) (Fig. $9 B$ ) and $99 \pm 1 \%$ by suramin $(200 \mu \mathrm{M} ; n=2)$. Together, these data indicate that ATP-dependent excitation of IHCs is responsible for generating bursts of activity in auditory nerves over a prolonged period of development, beginning at about P4 and concluding shortly after the onset of hearing (Fig. 10).

\section{Discussion}

To better understand the mechanisms responsible for generating spontaneous activity in the developing auditory system and define the period during which this activity occurs, we examined spontaneously generated activity in cochleae acutely isolated from young rats. In these preparations, ISCs released ATP from birth until just after the onset of hearing (Fig. 10). During this time, ATP induced inward currents, $\mathrm{Ca}^{2+}$ transients and morphological changes in ISCs, and periodically depolarized IHCs, leading to bursts of action potentials in SGNs. The period of ATP-induced activity in SGNs began several days after birth, as IHCs became responsive to ATP, and continued until the onset of hearing, when auditory neurons begin to display adult-like firing patterns (Walsh and Romand, 1992; Sonntag et al., 2009). These studies show that purinergic signaling is positioned to play a crucial role in the development of the auditory system by initiating activity in hair cells, supporting cells, and auditory neurons in the cochlea before the onset of hearing.

ATP-dependent excitation of IHCs in the developing cochlea Mammals such as mice, rats and cats are born deaf, and auditory thresholds remain high ( $>80 \mathrm{~dB}$ sound pressure level) for the first 10-12 postnatal days (Ehret, 1983). Nevertheless, both central auditory neurons and auditory nerve fibers exhibit lowfrequency electrical activity in vivo during most of the prehearing period (Walsh and Romand, 1992; Jones et al., 2007; Rodriguez-
$\mathrm{P} 1$ P4
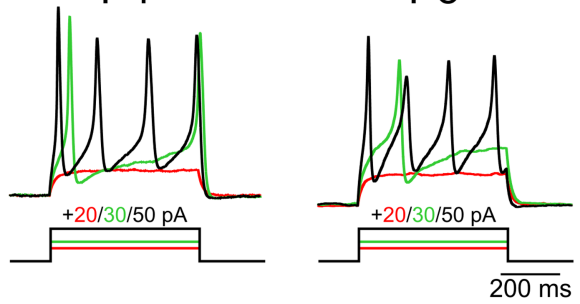

$\overline{200 \mathrm{~ms}}$

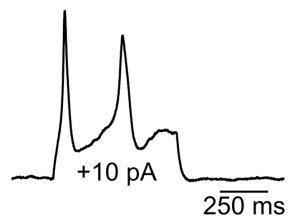

$2 \overline{50 \mathrm{~ms}}$
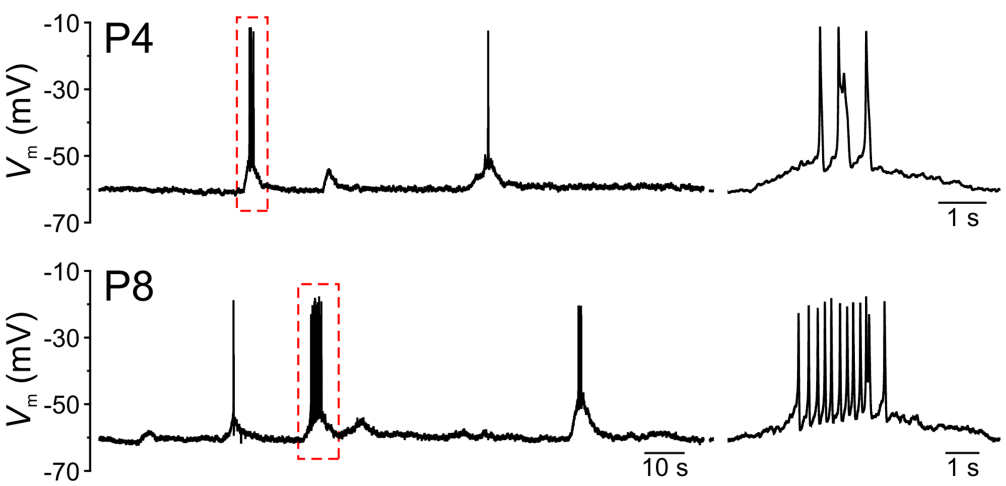

Figure 8. IHCs exhibit minimal intrinsically generated activity before the onset of hearing. $A$, Membrane potential changes in three current steps (amplitudes indicated above) and their corresponding responses are shown: the largest step that failed to

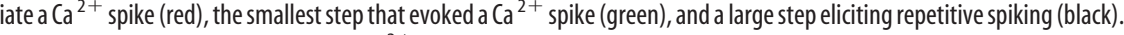
spiked in response to a $10 \mathrm{pA}$ current step (shown at the right). Middle, bottom, Spontaneous ATP-dependent depolarizations occasionally trigger bursts of $\mathrm{Ca}^{2+}$ spikes. On the right, the bursts highlighted by the dashed red boxes are shown on an expanded time scale. All recordings were performed in $6 \mathrm{~mm}\left[\mathrm{~K}^{+}\right]_{\mathrm{e}}$.

Contreras et al., 2009). In contrast to the quasi-random patterns of activity recorded from auditory neurons after hearing onset, "spontaneous" activity during the prehearing period consists of discrete bursts of action potentials separated by long periods of quiescence (Lippe, 1994; Jones et al., 2001, 2007; RodriguezContreras et al., 2009; Sonntag et al., 2009). It is likely that this activity is initiated within the developing cochlea, because bursts of action potentials have been recorded from SGNs (Jones et al., 2001, 2007), which receive direct input from IHCs, and burst firing of central auditory neurons in embryonic chicks was abolished by removal of the cochlea or application of the sodium channel blocker tetrodotoxin to the oval window (Lippe, 1994). These results indicate that the stimulus responsible for initiating periodic burst activity in auditory neurons resides within the cochlea, and that it is prevalent during the prehearing period but ends shortly after hearing onset. Our previous studies indicate that supporting cells within Kölliker's organ, a mass of columnarshaped cells located immediately medial to IHCs in the developing cochlea, periodically release ATP, which depolarizes nearby IHCs leading to bursts of action potentials in postsynaptic SGNs (Tritsch et al., 2007). Here we show that the developmental time course and properties of purinergic signaling between supporting cells and IHCs fulfill the criteria expected for the stimulus that initiates spontaneous activity in the auditory pathway before 


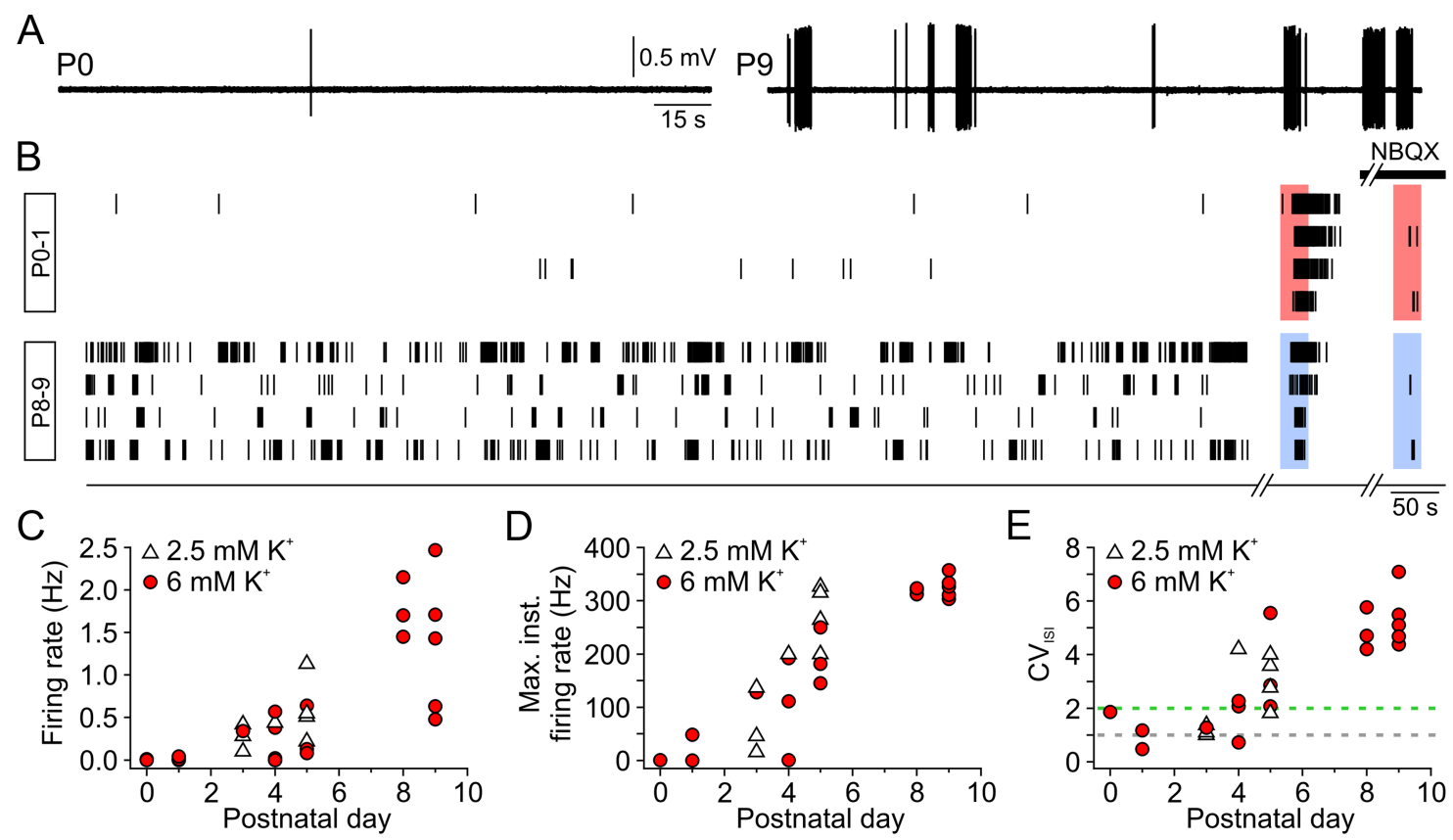

Figure 9. Developmental changes in spontaneous SGN firing. $\boldsymbol{A}$, Continuous loose-patch recordings from representative PO (left) and P9 (right) SGNs. $\boldsymbol{B}$, Raster plots of spontaneous action potentials from four other P0 - P1 SGNs (top) and four other P8 - P9SGNs (bottom) in ACSF containing $6 \mathrm{~mm} \mathrm{KCl.} \mathrm{Each} \mathrm{recording} \mathrm{was} \mathrm{concluded} \mathrm{by} \mathrm{two} \mathrm{brief} \mathrm{bath} \mathrm{applications} \mathrm{of} \mathrm{ACSF} \mathrm{containing} \mathrm{either}$ $30 \mathrm{~mm} \mathrm{KCl}$ (red boxes; $\mathrm{P0}-\mathrm{P} 1$ ) or $100 \mu \mathrm{m}$ ATP (blue boxes; $\mathrm{P8}-\mathrm{P9}$ ) in the absence or presence (black bar) of NBQX (10-20 $\mu \mathrm{M})$. C $\boldsymbol{E}$, Graphs of average firing rate $(\boldsymbol{C})$, maximum instantaneous firing rate $(\boldsymbol{D})$, and coefficient of variation of interspike intervals $(\mathrm{CV} \mid \mathrm{ISj} ; \boldsymbol{E})$ for individual $\mathrm{SGN}$ recordings at indicated ages $(n=6,17$, and 8 at $\mathrm{PO}-\mathrm{P} 1, \mathrm{P3}-\mathrm{P} 5$, and $\mathrm{P} 8-\mathrm{P} 9$, respectively) in either $2.5 \mathrm{mM}$ (white triangle) or $6 \mathrm{~mm} \mathrm{KCI}$ (red circle). $\mathrm{CV}_{\mathrm{ISI}}$ values of $\sim 1$ (gray dashed line) and $>2$ (green dashed line) indicate random and burst firing, respectively.

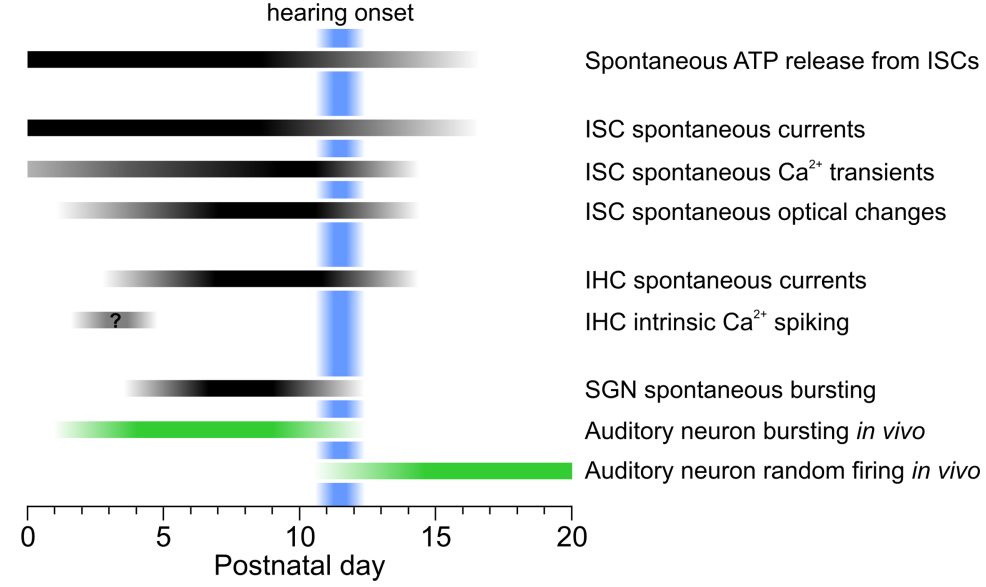

Figure 10. Developmental changes in spontaneous cochlear activity during the first three postnatal weeks in rat. Black bars indicate postnatal ages during which a particular form of activity was observed, and the shaded regions approximate the ages during which the frequency of these activities changed. The day of birth is considered PO. The blue shaded area represents the period when hearing begins. Green bars represent the timing of spontaneous bursting and random action potential firing patterns recorded in vivo from auditory neurons in mouse, rat, and cat (obtained from Walsh and Romand, 1992; Jones et al., 2007; Rodriguez-Contreras et al., 2009; Sonntag et al., 2009).

hearing onset. Morphologically distinct synapses are established between IHCs and SGNs embryonically (Pujol et al., 1998), and depolarization of IHCs in P0 cochleae leads to increases in capacitance (Beutner and Moser, 2001; Johnson et al., 2005) and action potential bursts in SGNs (Fig. 9), indicating that IHCs are capable of $\mathrm{Ca}^{2+}$-dependent transmitter release almost 2 weeks before hearing onset. This early maturation of IHC-afferent synapses is essential to propagate spontaneous activity out of the cochlea, because SGNs require input from IHCs to initiate firing during the prehearing period (Fig. 9) (Tritsch et al., 2007). Local release of ATP from discrete sites along the organ of Corti leads to periodic excitation of groups of IHCs, and the slow time course of ATPinduced events in IHCs is consistent with the prolonged bursts of action potentials observed in auditory neurons (Jones et al., 2001, 2007; RodriguezContreras et al., 2009; Sonntag et al., 2009). Although IHCs exhibit a high threshold for transmitter release during the prehearing period (Beutner and Moser, 2001; Johnson et al., 2005), a proportion of the ATP-induced depolarizations were of sufficient amplitude to trigger $\mathrm{Ca}^{2+}$ spikes and promote neurotransmitter release. Unlike the developing visual system, where the mechanisms responsible for triggering spontaneous retinal waves vary with age before eye opening (Huberman et al., 2008), SGN bursting relies exclusively on ATP-mediated excitation of IHCs throughout the postnatal prehearing period. Together, these studies suggest that purinergic signaling in the developing organ of Corti plays an essential role in generating spontaneous activity in developing auditory circuits.

\section{Developmental time course of spontaneous} purinergic signaling

Recordings from supporting cells and IHCs indicate that spontaneous activity ceases abruptly after hearing onset, at a time when both cell types remain responsive to ATP. Our prior studies suggest that connexin $(\mathrm{Cx})$ hemichannels may allow release of ATP from ISCs, because spontaneous ATP-mediated currents were inhibited by the gap junction blockers octanol and carbenoxa- 
lone, and their frequency increased when extracellular $\mathrm{Ca}^{2+}$ was reduced (Tritsch et al., 2007), a manipulation that enhances hemichannel opening (Gomez-Hernandez et al., 2003). However, it is unlikely that the age-dependent decline in purinergic signaling results from a decrease in connexin expression, because both $\mathrm{Cx} 26$ and $\mathrm{Cx} 30$ remain highly expressed by ISCs in the mature cochlea (Forge et al., 2003). It is possible that a higher proportion of unpaired connexons exist at the surface of ISCs during early development of the organ of Corti, and that orphaned channels are removed after the onset of hearing, although it is equally plausible that whatever signal triggers hemichannel opening is diminished with age.

One aspect of development that is likely to contribute to the decline in ATP release is the reduction in the number of ISCs, which are progressively removed through programmed cell death during postnatal development (Knipper et al., 1999; Kamiya et al., 2001). The regression of Kölliker's organ is almost complete in the apical region of the cochlea by the end of the second postnatal week in rodents (Wada, 1923; Kraus and Aulbach-Kraus, 1981), when spontaneous purinergic activity is no longer present and the cochlea becomes functionally mature. The absence of these cells in the mature cochlea suggests that one of the primary functions of Kölliker's organ may be to initiate spontaneous activity in the auditory pathway and facilitate the maturation of hair cells and auditory neurons. It is possible that burst firing emerges and subsides earlier in SGNs that receive input from the basal region of the cochlea, as our recordings were limited to the apical region of the cochlea, which is developmentally less mature (Lim and Rueda, 1992). Such a base-to-apex gradient in activity patterns could provide information about the location of SGNs along the tonotopic axis to help facilitate tonotopic refinement of connections among auditory neurons in the CNS.

Although our results indicate that spontaneous ATP release ends as hearing begins, gap-junction-dependent ATP release has also been measured from cochleae isolated from mature animals (Zhao et al., 2005). Moreover, prolonged noise exposure has been associated with elevations of ATP in the endolymph (Muñoz et al., 2001), and administration of ATP analogs or purinergic receptor antagonists directly to the cochlea affect the endocochlear potential and sound processing (Muñoz et al., 1995; Chen et al., 1998), indicating that purinergic signaling continues to play an important role in auditory function in adulthood. The source of this ATP and the mechanisms responsible for release in the mature cochlea remain to be determined.

\section{Contribution of intrinsic and extrinsic sources to IHC activity}

Previous studies have reported that IHCs in prehearing cochleae fire $\mathrm{Ca}^{2+}$ spikes continuously in the absence of external input (Kros et al., 1998; Marcotti et al., 2003; Brandt et al., 2007). To account for the intermittent pattern of activity observed in the auditory nerve in vivo, it has been suggested that tonic IHC firing is periodically interrupted by inhibitory input from cholinergic efferents (Walsh and Romand, 1992; Köppl, 2007), which form synapses with IHCs only during the prehearing period (Pujol et al., 1998). Although our results do not exclude a role for efferents in vivo, this input does not appear to be necessary for the generation of action potential bursts in SGNs, because these central projections are severed during cochlea isolation. However, the issue of whether IHCs fire continuously in the developing cochlea remains unresolved. It has been reported that IHCs are active only during the early prehearing period in mouse (P0-P6) (Marcotti et al., 2003; Brandt et al., 2007) and only during the late prehear- ing period in rat (P7-P11) (Brandt et al., 2007), although tonic $\mathrm{IHC} \mathrm{Ca}^{2+}$ spiking has been observed without current injection in P7-P8 mice (Seal et al., 2008), and external input was required to elicit IHC Ca ${ }^{2+}$ spikes in P2-P6 mice (Marcotti et al., 1999) and in P7-P11 rats (Glowatzki and Fuchs, 2000; Goutman et al., 2005). In our rat preparations, the resting membrane potential of IHCs was significantly more hyperpolarized than the threshold for $\mathrm{Ca}^{2+}$ spike initiation throughout the postnatal prehearing period. Although a few SGNs exhibited nonburst activity and a $\mathrm{CV}_{\text {ISI }}$ near unity during the period when IHCs first became active (P3-P5), little to no activity was observed in IHCs or SGNs for the first two postnatal days, and SGN discharge consisted primarily of discrete ATP-dependent bursts between P4 and P9. These results suggest that intrinsic activity of IHCs does not play a prominent role in the initiation of auditory nerve firing before hearing onset. In support of this conclusion, in vivo recordings have shown that SGNs in P3-P9 kittens (Jones et al., 2007) and neurons in the auditory brainstem of prehearing rats (P1-P8) (Rodriguez-Contreras et al., 2009) and mice (P8-P10) (Sonntag et al., 2009) exhibit burst firing similar to that observed in SGNs in cultured (Tritsch et al., 2007) and acutely isolated cochleae (Fig. 9).

\section{Additional consequences of purinergic signaling in the developing cochlea}

IHCs undergo dramatic physiological changes during the prehearing period that enable them to release transmitter in a graded manner in response to small deviations in membrane potential (Johnson et al., 2005). Previous studies have shown that $\mathrm{Ca}_{\mathrm{V}} 1.3$ $\mathrm{Ca}^{2+}$ channels, which carry most of the $\mathrm{Ca}^{2+}$ current in IHCs (Platzer et al., 2000), are necessary for morphological maturation of ribbons, upregulation of large-conductance $\mathrm{Ca}^{2+}$-activated $\mathrm{K}^{+}$channels (BK channels), and withdrawal of efferents from IHCs at the onset of hearing (Brandt et al., 2003; Glueckert et al., 2003). By initiating depolarization of IHCs and gating of these $\mathrm{Ca}^{2+}$ channels, ATP may promote the functional maturation of IHCs. In addition, our previous studies indicate that purinergic receptors are also present postsynaptically in the afferent dendrite of type I SGNs (Tritsch et al., 2007). Although the current carried through these receptors alone is not sufficient to induce firing, they may effectively boost synaptic potentials and help refine the pattern of afferent innervation (Greenwood et al., 2007).

One of the most unusual aspects of purinergic signaling in the developing cochlea is the morphological changes exhibited by ISCs within Kölliker's organ. Although this study did not directly address the molecular mechanisms responsible for this crenation, we speculate that the rise in intracellular $\mathrm{Ca}^{2+}$ that follows activation of purinergic receptors opens $\mathrm{Ca}^{2+}$-activated $\mathrm{Cl}^{-}$channels leading to $\mathrm{Cl}^{-}$efflux, similar to that described in exocrine glands and airway epithelia (Kidd and Thorn, 2000; Lee et al., 2007). Given the high resting membrane potential of ISCs, activation of these channels would be expected to contribute to the inward current produced by ATP (Lagostena et al., 2001), cause water efflux, and induce membrane crenation. Indeed, it has been suggested previously that cochlear supporting cells secrete water (Sobkowicz et al., 1993). If this pathway is activated in ISCs, Kölliker's organ may participate in the formation of the endolymphatic (cochlear duct) or perilymphatic (scala tympani) compartments during the second postnatal week. Alternatively, these changes in shape may result from the activation of contractile proteins in ISCs. Regardless of the mechanism, the coordinated contraction of groups of ISCs could facilitate detachment 
of the overlaying tectorial membrane, which is fused to the apical surface of ISCs during the early prehearing period (Hinojosa, 1977; Lim and Rueda, 1992). In addition, movements of Kölliker's organ in response to large ATP release events can displace IHCs (Tritsch and Bergles, unpublished observations), which may induce hair bundle deflection and provide additional depolarization to promote $\mathrm{Ca}^{2+}$ spiking. Although this study examined ISCs, IHCs, and SGNs, ATP receptors are also expressed by outer hair cells (Nakagawa et al., 1990) and other classes of supporting cells (Lagostena et al., 2001; Piazza et al., 2007). A greater understanding of the actions of ATP on the various cell types in the organ of Corti, and the mechanisms that regulate ATP release, may help reveal new roles for this activity in the development and dysfunction of the auditory system.

\section{References}

Anniko M, Wroblewski R (1986) Ionic environment of cochlear hair cells. Hear Res 22:279-293.

Beutner D, Moser T (2001) The presynaptic function of mouse cochlear inner hair cells during development of hearing. J Neurosci 21:4593-4599.

Brandt A, Striessnig J, Moser T (2003) CaV1.3 channels are essential for development and presynaptic activity of cochlear inner hair cells. J Neurosci 23:10832-10840.

Brandt N, Kuhn S, Munkner S, Braig C, Winter H, Blin N, Vonthein R, Knipper M, Engel J (2007) Thyroid hormone deficiency affects postnatal spiking activity and expression of $\mathrm{Ca}^{2+}$ and $\mathrm{K}^{+}$channels in rodent inner hair cells. J Neurosci 27:3174-3186.

Chen C, Skellett RA, Fallon M, Bobbin RP (1998) Additional pharmacological evidence that endogenous ATP modulates cochlear mechanics. Hear Res 118:47-61.

Ehret G (1983) Development of hearing and response behavior to sound stimuli: behavioral studies. In: Development of auditory and vestibular systems, Chap 7 (Romand R, ed), pp 211-237. New York: Academic.

Erazo-Fischer E, Striessnig J, Taschenberger H (2007) The role of physiological afferent nerve activity during in vivo maturation of the calyx of Held synapse. J Neurosci 27:1725-1737.

Forge A, Becker D, Casalotti S, Edwards J, Marziano N, Nevill G (2003) Gap junctions in the inner ear: comparison of distribution patterns in different vertebrates and assessment of connexin composition in mammals. J Comp Neurol 467:207-231.

Gale JE, Piazza V, Ciubotaru CD, Mammano F (2004) A mechanism for sensing noise damage in the inner ear. Curr Biol 14:526-529.

Glowatzki E, Fuchs PA (2000) Cholinergic synaptic inhibition of inner hair cells in the neonatal mammalian cochlea. Science 288:2366-2368.

Glowatzki E, Fuchs PA (2002) Transmitter release at the hair cell ribbon synapse. Nat Neurosci 5:147-154.

Glueckert R, Wietzorrek G, Kammen-Jolly K, Scholtz A, Stephan K, Striessnig J, Schrott-Fischer A (2003) Role of class D L-type $\mathrm{Ca}^{2+}$ channels for cochlear morphology. Hear Res 178:95-105.

Gomez-Hernandez JM, de Miguel M, Larrosa B, Gonzalez D, Barrio LC (2003) Molecular basis of calcium regulation in connexin-32 hemichannels. Proc Natl Acad Sci U S A 100:16030-16035.

Goutman JD, Fuchs PA, Glowatzki E (2005) Facilitating efferent inhibition of inner hair cells in the cochlea of the neonatal rat. J Physiol 566:49-59.

Greenwood D, Jagger DJ, Huang LC, Hoya N, Thorne PR, Wildman SS, King BF, Pak K, Ryan AF, Housley GD (2007) P2X receptor signaling inhibits BDNF-mediated spiral ganglion neuron development in the neonatal rat cochlea. Development 134:1407-1417.

Hinojosa R (1977) A note on development of Corti's organ. Acta Otolaryngol 84:238-251.

Huberman AD, Feller MB, Chapman B (2008) Mechanisms underlying development of visual maps and receptive fields. Annu Rev Neurosci 31:479-509.

Jagger DJ, Forge A (2006) Compartmentalized and signal-selective gap junctional coupling in the hearing cochlea. J Neurosci 26:1260-1268.

Johnson SL, Marcotti W, Kros CJ (2005) Increase in efficiency and reduction in $\mathrm{Ca}^{2+}$ dependence of exocytosis during development of mouse inner hair cells. J Physiol 563:177-191.

Jones TA, Jones SM, Paggett KC (2001) Primordial rhythmic bursting in embryonic cochlear ganglion cells. J Neurosci 21:8129-8135.
Jones TA, Leake PA, Snyder RL, Stakhovskaya O, Bonham B (2007) Spontaneous discharge patterns in cochlear spiral ganglion cells before the onset of hearing in cats. J Neurophysiol 98:1898-1908.

Kamiya K, Takahashi K, Kitamura K, Momoi T, Yoshikawa Y (2001) Mitosis and apoptosis in postnatal auditory system of the $\mathrm{C} 3 \mathrm{H} / \mathrm{He}$ strain. Brain Res 901:296-302.

Kandler K, Clause A, Noh J (2009) Tonotopic reorganization of developing auditory brainstem circuits. Nat Neurosci 12:711-717.

Kelley MW (2007) Cellular commitment and differentiation in the organ of Corti. Int J Dev Biol 51:571-583.

Khazipov R, Sirota A, Leinekugel X, Holmes GL, Ben-Ari Y, Buzsaki G (2004) Early motor activity drives spindle bursts in the developing somatosensory cortex. Nature 432:758-761.

Kidd JF, Thorn P (2000) Intracellular $\mathrm{Ca}^{2+}$ and $\mathrm{Cl}^{-}$channel activation in secretory cells. Annu Rev Physiol 62:493-513.

Knipper M, Gestwa L, Ten Cate WJ, Lautermann J, Brugger H, Maier H, Zimmermann U, Rohbock K, Kopschall I, Wiechers B, Zenner HP (1999) Distinct thyroid hormone-dependent expression of TrKB and p75NGFR in nonneuronal cells during the critical TH-dependent period of the cochlea. J Neurobiol 38:338-356.

Köppl C (2007) Spontaneous generation in early sensory development. Focus on "spontaneous discharge patterns in cochlear spiral ganglion cells before the onset of hearing in cats." J Neurophysiol 98:1843-1844.

Kraus HJ, Aulbach-Kraus K (1981) Morphological changes in the cochlea of the mouse after the onset of hearing. Hear Res 4:89-102.

Kros CJ, Ruppersberg JP, Rüsch A (1998) Expression of a potassium current in inner hair cells during development of hearing in mice. Nature 394:281-284.

Lagostena L, Ashmore JF, Kachar B, Mammano F (2001) Purinergic control of intercellular communication between Hensen's cells of the guinea-pig cochlea. J Physiol 531:693-706.

Lee RJ, Limberis MP, Hennessy MF, Wilson JM, Foskett JK (2007) Optical imaging of $\mathrm{Ca}^{2+}$-evoked fluid secretion by murine nasal submucosal gland serous acinar cells. J Physiol 582:1099-1124.

Lim DJ, Rueda J (1992) Structural development of the cochlea. In: Development of auditory and vestibular systems 2, Chap 2 (Romand R, ed), pp 33-58. Amsterdam: Elsevier.

Lippe WR (1994) Rhythmic spontaneous activity in the developing avian auditory system. J Neurosci 14:1486-1495.

Marcotti W, Geleoc GS, Lennan GW, Kros CJ (1999) Transient expression of an inwardly rectifying potassium conductance in developing inner and outer hair cells along the mouse cochlea. Pflugers Arch 439:113-122.

Marcotti W, Johnson SL, Holley MC, Kros CJ (2003) Developmental changes in the expression of potassium currents of embryonic, neonatal and mature mouse inner hair cells. J Physiol 548:383-400.

McKay SM, Oleskevich S (2007) The role of spontaneous activity in development of the endbulb of Held synapse. Hear Res 230:53-63.

Meister M, Wong RO, Baylor DA, Shatz CJ (1991) Synchronous bursts of action potentials in ganglion cells of the developing mammalian retina. Science 252:939-943.

Mostafapour SP, Cochran SL, Del Puerto NM, Rubel EW (2000) Patterns of cell death in mouse anteroventral cochlear nucleus neurons after unilateral cochlea removal. J Comp Neurol 426:561-571.

Müller M (1991) Developmental changes of frequency representation in the rat cochlea. Hear Res 56:1-7.

Muñoz DJ, Thorne PR, Housley GD, Billett TE, Battersby JM (1995) Extracellular adenosine $5^{\prime}$-triphosphate (ATP) in the endolymphatic compartment influences cochlear function. Hear Res 90:106-118.

Muñoz DJ, Kendrick IS, Rassam M, Thorne PR (2001) Vesicular storage of adenosine triphosphate in the guinea-pig cochlear lateral wall and concentrations of ATP in the endolymph during sound exposure and hypoxia. Acta Otolaryngol 121:10-15.

Nakagawa T, Akaike N, Kimitsuki T, Komune S, Arima T (1990) ATPinduced current in isolated outer hair cells of guinea pig cochlea. J Neurophysiol 63:1068-1074.

O'Leary DD, Chou SJ, Sahara S (2007) Area patterning of the mammalian cortex. Neuron 56:252-269.

Piazza V, Ciubotaru CD, Gale JE, Mammano F (2007) Purinergic signaling and intercellular $\mathrm{Ca}^{2+}$ wave propagation in the organ of Corti. Cell Calcium 41:77-86.

Platzer J, Engel J, Schrott-Fischer A, Stephan K, Bova S, Chen H, Zheng H, 
Striessnig J (2000) Congenital deafness and sinoatrial node dysfunction in mice lacking class D L-type $\mathrm{Ca}^{2+}$ channels. Cell 102:89-97.

Pujol R, Lavigne-Rebillard M, Lenoir M (1998) Development of sensory and neural structures in the mammalian cochlea. In: Development of the auditory system, Chap 4 (Rubel EW, Popper AN, Fay RR, eds), pp 146192. New York: Springer.

Rodriguez-Contreras A, Rusu SI, Borst JG (2009) Synaptic inputs drive bursts of action potentials in the rat auditory brainstem before the onset of hearing. Assoc Res Otolaryngol Abstr 32:373.

Seal RP, Akil O, Yi E, Weber CM, Grant L, Yoo J, Clause A, Kandler K, Noebels JL, Glowatzki E, Lustig LR, Edwards RH (2008) Sensorineural deafness and seizures in mice lacking vesicular glutamate transporter 3. Neuron 57:263-275.

Sobkowicz HM, Loftus JM, Slapnick SM (1993) Tissue culture of the organ of Corti. Acta Otolaryngol Suppl 502:3-36.
Sonntag M, Englitz B, Kopp-Scheinpflug C, Rübsamen R (2009) Early postnatal development of spontaneous and acoustically evoked discharge activity of principal cells of the medial nucleus of the trapezoid body: an in vivo study in mice. J Neurosci 29:9510-9520.

Tritsch NX, Yi E, Gale JE, Glowatzki E, Bergles DE (2007) The origin of spontaneous activity in the developing auditory system. Nature 450: $50-55$.

Wada T (1923) Anatomical and physiological studies on the growth of the inner ear of the albino rat. Am Anat Mem 10:1-174.

Walsh EJ, Romand R (1992) Functional development of the cochlea and the cochlear nerve. In: Development of auditory and vestibular systems 2, Chap 6 (Romand R, ed), pp 161-210. Amsterdam: Elsevier.

Zhao HB, Yu N, Fleming CR (2005) Gap junctional hemichannel-mediated ATP release and hearing controls in the inner ear. Proc Natl Acad Sci U S A 102:18724-18729. 